\title{
Küresel E-Ticaret Sisteminde Kullanılan Elektronik Ticaret Gümrük Beyannamesinin Posta ve Hızlı Kargo Taşımacılığına Etkileri ${ }^{1}$
}

\author{
DOI: $10.26466 /$ opus.861576 \\ * \\ Aynur Acer* - Celil Yügünt ** \\ * Dr. Öğr. Üyesi, İstanbul Arel Üniversitesi İ.̇.B.F., İstanbul/Türkiye \\ E-Posta: aynuracer@arel.edu.tr \\ ORCID: $\quad \underline{0000-0002-7315-7020}$ \\ ** Uzman, Ticaret Bakanlığı, İstanbul/Türkiye \\ E-Posta: c.yugunt@ticaret.gov.tr \\ ORCID: $\quad \underline{0000-0003-3495-2539}$
}

\section{Öz}

Internet kullanımının yaygınlaşmasıyla dünya ticaretinde e-ticaret işlem hacmi günden güne hızla artmaktadır. Kişiler veya firmalarm talep ettikleri bir ürünü belirli standartlarda ve daha düşük maliyetle tedarik etme isteği e-ticarete olan bu talebi pozitif etkilemektedir. Birçok kullanıcı hem basit hem de kullanışlı bir sistem olduğu için e-ticaret üzerinden sipariş vermeyi tercih etmektedir. Küresel çapta e-ticaret işlem hacminin artmasıyla gönderilere uygulanan gümrük işlemleriyle ilgili daha fazla bilgiye ihtiyaç duyulmaktadır. Aynı zamanda her gönderi de o ülkenin ticaret politikası önlemlerine tabi tutulur. Bu gümrük işlemleri kişi veya firmalar adına dolaylı temsil yetkisi kapsamında posta ve hızlı kargo taşımacılı̆ğ yetkisine sahip firmalar tarafindan yapılmaktadır. Posta ve hızh kargo taşımacılı̆̆ kapsamında yapılan ihracat ve ithalat gönderilerinin gümrük prosedürlerinin daha basit ve kısa sürede yapılabilmesi için başvurulan yollardan birisi de Elektronik Ticaret Gümrük Beyannamesi (ETGB) düzenlenmesidir. Gümrük değeri belirli bir değer ve miktarda olan ürünler için maktu vergilendirme yapılarak, ticari değeri olmayan numune ve döküman gibi gönderiler ETGB'ye tabi tutulmaktadır. Bu çalışmada ETGB süreci ve işleyişi hakkında bilgi verilerek bu sürecinin firsatlarl, tehditleri, üstünlükleri ve zayıflıkları SWOT analiziyle belirlenmeye çalışılmıştır. Aynı zamanda sürecin daha da iyileştirilmesi için önerilerde bulunulmuştur. Çalışmanın yazında bu konuda yapılmış sınırlı çalışma olmasından dolayı literature katkı sağlayacağı düşünülmektedir.

Anahtar Kelimeler: Elektronik Ticaret Gümrük Belgesi, ETGB, Posta ve Hızlı Kargo Taşımacılığı, Swot Analizi.

\footnotetext{
${ }^{1}$ Bu çalışma Dr. Aynur ACER danışmanlığında, Celil YÜGÜNT tarafından hazırlanan "Türkiye'de elektronik ticaret gümrük beyannamesi sürecinin işleyişi ve swot analizi" başılılı yüksek lisans tezinden türetilmiştir.
} 


\title{
The Effects of Electronic Trade Customs Declaration Used in Global E-Commerce System on Post and Express Cargo Transportation
}

\begin{abstract}
With the widespread use of the internet, e-commerce transaction volume in world trade is increasing day by day. The desire of individuals or companies to supply a product they demand at certain standards and at a lower cost positively affects the demand for e-commerce. Many users prefer to order via ecommerce as it is both a simple and useful system. With the increasing volume of e-commerce transactions globally, more information is needed regarding the customs procedures applied to shipments. They are also subject to trade policy measures of that country in each shipment. These customs procedures are carried out on behalf of individuals or companies within the scope of indirect representation authority, by companies authorized for post and express cargo transportation. One of the ways to make the customs procedures of export and import shipments made within the scope of post and express cargo transportation in a simpler and shorter time is the Electronic Trade Customs Declaration (ETCD). Products with a certain value and amount of customs value and shipments such as samples and documents without commercial value are subject to ETCD. ETCD is also trying to alleviate the workload of customs administrations. In this study, by giving information about the ETGB process and its operation, strengths, weaknesses, opportunities and threats of this process have been tried to be determined by SWOT analysis. At the same time, suggestions were made for further improvement of the process. It is thought that the study will contribute to the literature due to the limited number of studies on this subject in the literature.
\end{abstract}

Keywords: Electronic Trade Customs Declaration, ETCD, Post and Express Cargo Transportation, Swot Analysis 


\section{Giriş}

Son yıllarda internet kullanımının yaygınlaşması e-ticarete yeni bir ivme kazandırmış ve e-ticaretle ilgili işlemlerin elektronik ortamda gerçekleştirilmesi mümkün hale gelmiştir. Hem kolay hem de kullanışlı bir sistem olan e-ticaret sistemi, siparişin kolay ve hızlı alınması, kullanıcı arayüzlerinin basit olması, e-ticaret alt yapısının güçlü olması ve satın alma işlemlerinin güvenilirliği gibi birçok nedenden dolayı kullanıcılar tarafından kısa sürede benimsenmiştir. Sistem ulusal veya uluslararası hizmet sunan birçok tedarikçi firmanın faaliyetlerinin bütününden oluşmaktadır. Yurtiçi verilen siparişlerde mevzuat açısından çok fazla yükümlülük olmamakla birlikte küresel e-ticaret firmalarından (Alibaba, Ali Express, Amazon vb.) verilen siparişlerde ürünün ülkeye girişinde gümrük mevzuatı kaynaklı sorumluluklar meydana gelmektedir.

Her uluslararası hizmet veren e-ticaret sisteminin işleyişinde ilgili ülkelerin ticaret politikası önlemleri etkili olmaktadır. Kullanıcılar tarafından verilen herhangi bir sipariş ilgili ülke için riskli veya tehlikeli olabilir ve belirli bir oranda vergi matrahı oluşturabilir. Bu durumda sipariş veren kurum veya birey adına işlemleri gerçekleştirmek için dolaylı temsil yoluyla süreçleri izleyen posta ve hızlı kargo taşımacılığ yetki belgesine sahip kurumlar aracılık etmektedir. Bu yetkilendirilmiş operatörler gümrük idarelerinde kullanılan Bilgisayarlı Gümrük Etkinlikleri Sistemi (BİLGE) aracılığıyla kullanıcıları adına “Elektrik Ticaret Gümrük Beyannamesi (ETGB)" oluşturmaktadır (Canpolat, 2001: 42). Bu operatörler ayrıca kendi bünyelerinde çalıştırdıkları gümrük idareleriyle sürekli etkileşimde olan gümrük müşavirleri sayesinde verilen siparişlerin kanun ve mevzuata uygunluğunu araştırarak kullanıcıları bilgilendirmekte ve herhangi bir cezai işlemle karşılaşılmaması için çalışmaktadır. Bu süreçte Türkiye'de e-ticarette uygulanan yöntemlerinden biri olan ETGB, hem ülke ekonomisi hem de ulusal güvenlik açısından son derece önemlidir ve son yıllarda ülkelerarası yapılan e-ticaret işlemlerinde kullanımı gittikçe artmaya başlamıştır.

Küresel e-ticaret sisteminin işlem hacminde meydana gelen artış ve dünya çapında vergilendirme boyutunun ülkeden ülkeye değişiklik göstermesi günümüzde ETGB'nin önemini ortaya çıkarmış ve bu 
çalışmanın da konusunu oluşturmuştur. Kullanıcıların sistem hakkında yeterli bilgiye sahip olmaması, kaynak eksikliğine bağlı olarak kişilerin veya kurumların mağdur edilmesine ve bunun sonucunda gümrük idarelerinin iş yükününde artışlara neden olmaktadır. Bu nedenle bu çalışmada literatürde çok rastlanmayan bir konu olan ve Türkiye'de son yıllarda uygulama alanı bulan ETGB sisteminin işleyişi hakkında bilgi verilmiş ve uzman görüşleri yardımıyla SWOT analizi yöntemiyle ele alınarak sistemin güçlü ve zayıf yönleri ile iç ve diş faktörlerden kaynaklanan fırsatlar ve tehditleri değerlendirilmiştir. Çalışmanın daha önce bu konuda yapılan bir çalışma olmaması nedeniyle literatüre katkı sağlayacağı düşünülmektedir.

\section{ETGB Sürecinin İşleyişi}

Türkiye' de 35-40 yıllık bir geçmişi olan posta ve kargo taşımacılığ günümüzde büyük bir ivme kazanmıştır. Bu sektörün Türkiye'de 100 binden fazla kişiye istihdam sağlayarak ülkemize önemli bir katma değer sağladığı bilinmekte ve 25 bin araç ile 10 bin sabit merkezde günde 7 Milyon adres ziyareti ve günlük 5 Milyon kilometre yol kat edilmektedir (Kut, 2017). Kullanıcılara güvenilirlik, hız, izlenebilirlik, kapıdan kapıya teslimat, kişiye özel teslimat gibi çeşitli avantajlar sunan posta ve hızlı kargo taşımacılığı hizmetleri bazı evrak, paket veya eşya taşımalarında kullanılan normal posta ve kargo hizmetlerine oranla günümüzde daha fazla tercih edilmektedir (Elibol, 2004: 314). Bahsi geçen bu hizmetlerde zaman faktörünün önemini kavrayan gümrük idareleri bazı basitleştirilmiş uygulamaları devreye sokarak bu eşyaların gümrük beyanları ve kontrollerinin daha hızlı bir şekilde sonuçlandırılmasına yönelik hizmetler sunmaktadır. Posta ve hızlı kargo taşımacılığı kapsamında yurtdışından getirtilen eşyaların hangi usul ve esaslar çerçevesinde gümrük işlemlerine tabi tutulacağ 1 2009/ 15481 Sayılı "4458 Sayılı Gümrük Kanunu'nun Bazı Maddelerinin Uygulanması Hakkında Karar", 10.03.2013 tarihli Seri No:4 Gümrük Genel Tebliği (Posta ve Hizlı Kargo Taşımacılığı), 3 Aralık 2016 tarihli Seri No: 5 Gümrük Genel Tebliği ve 29 Haziran 2019 tarihli Seri No:6 Gümrük Genel Tebliği kararlarında belirtilmektedir. Yetkilendirilmiş dolaylı operatörler yürürlükte olan bu mevzuatları dikkate alıp avantajlarından yararlanmak için bu kargo veya 
eşyanın ithalat veya ihracatında ETGB düzenlemektedir. Havayoluyla yapılan hızlı kargo taşımaları ETGB düzenlenerek gümrüklü sahalarda muhafaza edilir. Gümrük idaresi tarafından görevlendirilen muayene memurları ve müşavirler tarafından gümrüğe tabi olan ve olmayan eşyalar belirlenir. Ayrıca bu eşyaların yetkilendirilmiş firmalarca basitleştirilmiş usul esasına göre gümrük idarelerine beyanı mümkündür. Süreçteki tüm bu işlemlerin bazı kıymet ve miktar sınırlamaları göz önünde tutularak çok az sayıda firma tarafından gerçekleştirildiği görülmektedir.

Geleneksel ihracat işlemlerine karşı maliyet avantajı sağlamak ve gümrük işlemlerini hızlandırmak amacıyla 2013 yılında Türkiye'de gümrük mevzuatı yeniden düzenlenmiştir. Başlangıçta ihracat işlemlerinde 150 kilogramı ve $7500 €^{\prime}$ yu geçmeyen eşyalar ETGB'ye tabi tutulurken, Seri No:6 kararının düzenlenmesiyle brüt 300 kilogramı ve değeri $15000 \epsilon^{\prime}$ yu geçmeyen eşyalar standart ihracat işlemlerinden muaf tutularak ETGB'ye tabi tutulmuştur. Belirtilen bu eşya ağırlığı ve değeri, ülkeden ülkeye farklılık göstermektedir. $\mathrm{Bu}$ işlemin en önemli avantajlarından biri de beyanın gönderinin bir sonraki günü yapılabilmesi ve bu beyanname işlemlerinin gönderici yerine yetkilendirilmiş kargo firmaları tarafından gerçekleştirilmesidir. Bu düzenlemelerle birlikte eihracatın daha da kolaylaşması ve basitleştirilmesi amaçlanmaktadır (Şahbaz vd., 2014: 30). ETGB işlemlerini üç alt başlıkta de ğerlendirmek mümkündür;

İhracat işlemleri: 11.04.2018 günlü 30388 sayılı Resmî Gazete'de yayımlanan ve 26.11.2018 tarihinde yürürlüğe girecek olan 2018/11510 sayılı Karar ile 4458 Sayılı Gümrük Kanunu'nun Bazı Maddelerinin Uygulanması Hakkında Kararda Değişiklik Yapılmasına Dair Karar'ın 45, 62, 100 ve 126. maddelerinde değişikliğe gidilerek uygulamada "mikro ihracat" olarak adlandırılan brüt ağırlı̆̆ 300 kg. ve değeri 15000 Avro'yu geçmeyen posta ve hızlı kargo taşımacılığ konu olan eşyaya ETGB kapsamında ihracat işlemleri uygulanmaktadır. Bu kapsamda eşyaya uygulanacak olan ihracat işlemleri hızlı ve toplu bir şekilde yapilabilmektedir.

İthalat işlemleri: 2009/15481 sayılı Bakanlar Kurulu Kararının 126. Maddesi gereğince gümrük işlemlerine tabi olacak eşyalara işlem yapma yetkisi sınırlı sayıda posta ve kargo taşımacılığı yapan yetkili operatörlere 
verilmiştir. Yetkili operatörler aşağıda belirtilen eşyalara ETGB kapsamında işlemler uygulamaktadır (Gümrük Genel Tebliği, Seri No: 4):

- Belge,

- Değeri olmayan eşya,

- Numune eşya,

- Yolcu beraberinde gelen eşya,

- Bilimsel araştırma ve eğitim amacıyla gönderilen kitap veya bilimsel yayın,

- Brüt 30 kilogramı ve $1500 €^{\prime}$ yu geçmeyen ve ithalat rejimine tabi olacak eşya

Diğer işlemler: Bu süreçte 4458 sayılı Gümrük Kanunu ve Gümrük Yönetmeliği, Katma Değer Vergisi Kanunu, Vergi Usul Kanunu, Vergi Usul Kanunu Uygulama Tebliğleri dikkate alınmaktadır. Örneğin değeri olmayan kargo ile numune eşya veya modellerin ithali 4458 sayll Gümrük Kanunu'nun 167 nci maddesi gereğince gümrük vergisinden, 3065 sayılı KDV Kanunu'nun 16/b fikrası uyarınca KDV'den muaftır.

2014/7 Sayılı Genelge hükümlerince hızlı kargo taşımacılığında yasaklı veya kısıtlı sayılan ürünler ise şu şekildedir: uyusturucu veya uyarıcı etkiye sahip maddeler, alkol ve alkollü ürünler, yurtiçinde kaydı ve ruhsatı olmayan ateşli silah ve benzerleri, numune harici kozmetik ürünler, reçetesiz ilaçlar, tohumlar, drone, cep telefonları vb.

Yasaklı ve kısıtlı eşyalar haricinde belirtilen eşyaların havayoluyla yetkilendirilmiş hızlı kargo firmaları aracılığıyla taşınabilmesi için dolaylı temsil yetki belgesi, mikro ihracat gönderi bilgi formu, fatura ve ingilizce fatura ile birlikte vekalet verilmesi durumunda gümrük işlemleri hızlıca bu operatörler tarafından yapılabilmektedir. ETGB kapsamında gerçekleşen bir gönderinin hareket süreci Şekil 1'de verilmiştir.

Posta yoluyla Türkiye Gümrük Bölgesi'ne gelen, iade edilen veya Türkiye'den gönderilen eşya (mektuplar hariç) gümrük işlemlerine tabidir. Bu eşyalar gümrük bölgesine girdiği andan itibaren gümrük gözetimi altında posta idareleri veya yetkili operatörlere sevk edilerek gümrük işlemlerine tabi tutulurlar (Gümrük ve Ticaret Bakanlığı Yayınları, s.59). Eşyalar gerekli risk kriterleri temel alınarak belge veya fiziki kontrole tabi tutulduktan sonra posta idaresinin sorumluluğu ve gümrük idaresinin gözetimi altında 4458 sayılı Gümrük Kanunu'nun 93 
ile 107. maddesinde belirtilen hükümlere tabi gümrük idareleri gözetimindeki geçici depolama yerlerinde muhafaza edilir.

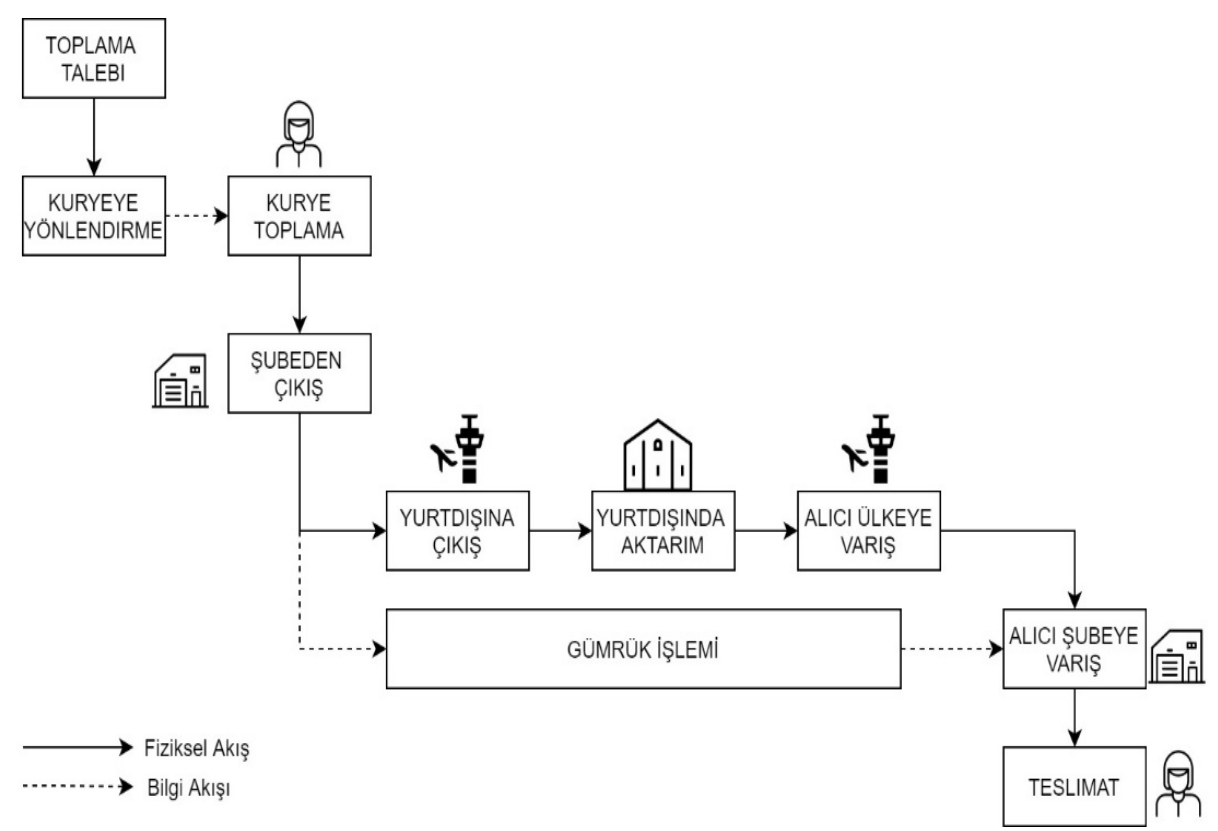

Şekil 1: Elektronik Ticaret Gümrük Beyannamesi (ETGB) Gönderi Süreci (Kaynak: DHL ETGB Sunumu, www.dhl.com.tr)

Türkiye'nin taraf olduğu uluslararası posta ve hızlı kargo anlaşmaları hükümleri eşyanın bu alanlarda bekleme süresini belirlemektedir. Posta ve hızlı kargo taşımacılı̆̆ı kapsamında yurtdışından gelen ürünlerin alıcılara tesliminde farklı uygulamalar söz konusudur.

Seri No: 5 kararına göre ithal eşyada 22 Euro altında olan gönderiler, hızlı kargo firmalarınca vekâletname alınmadan gümrük işlemleri muafiyet kapsaminda değerlendirilip adreslere teslim edilmekteydı. Ancak son çıkan Seri No: 6 kararına göre $30 \mathrm{~kg}$. ve 1500 Avro'yu geçmeyen ithal ürünlerde, ürünler $\mathrm{AB}$ ülkelerinden geldiği taktirde \%18, diğer ülkelerden geldiği taktirde $\% 20$ maktu vergisi talep edilmektedir. Posta ve hızlı kargo firmalarınca gümrük beyanı yapılan eşya için doğabilecek Gümrük Vergisi ve Kaynak Kullanım Destekleme Fonu (KKDF)'nun tahakkuk ve tahsilâtı gümrük idarelerince yapılmaktadır. 


\section{Literatür Taraması}

Literatürde Elektronik Ticaret Gümrük Beyannamesi (ETGB) ile ilgili bir araştırma yer almamakla birlikte posta ve hızlı kargo taşımacılığıyla ilgili sinırlı sayıda çalışmalar mevcuttur ve bu çalışmalar aşağıda belirtilmiştir.

Emek (2003), Devlet Planlama Teşkilati (DPT) kapsamında yapmış olduğu çalışmasında posta hizmetlerinin serbestleştirilmesi konusunu irdeleyerek özelleştirme, rekabet ve regülasyon konularına değinmiştir.

Deniz ve Gödekmerdan (2011), kargo firmalarının sunduğu hizmetlere yönelik müşterilerin tutum ve davranışlarını araştırdığı çalışmasında, 400 kişiye yüzyüze anket uygulamış ve kargo firması personelinin sorunları zamanında çözümlediğini, müşteriyi iyi bir biçimde karşıladığını, personelin yeterli deneyime sahip olduğunu ayrıca firmanın malları hasarsız olarak teslim ettiğini düşündükleri bulgusunu elde etmiştir.

Yıldız (2014) son değişikliklerle birlikte hızlı kargo taşımacılığını konu aldığı çalışmasında hızlı kargo taşımacılığı mevzuatına, yararlanılan muafiyetlere, eşyanın kontrolü ve müeyyideler ile bu sistemin kullanıcılara neler kazandırdığı konusuna değinmiştir.

Çınar (2014) çalışmasında posta ve hızlı kargo taşımacılığı sektöründe marka bağımlılığının oluşumunda örgüt kimliğinin önemine değinmiştir.

Atmaca ve Turgut (2015) çalışmalarında Türkiye'de hizmet veren kargo şirketlerinin seçimini etkileyen kriterleri değerlendirmiş ve fiyat, acil durum yönetimi veya çözüm bulma becerisi ve firmanın ekonomik geçmişi ve finansal istikrarı en önemli üç kriter olarak belirlemiştir.

Çakmak ve Özkan (2017) çalışmalarında kullanıcıların kargo firmalarını değerlendirmelerini önem-başarım analizi ile ölçmüştür. Çalışma sonucunda kullanıcıların değer verdiği en önemli hususlar gönderinin eksiksiz teslimi, açılıp kurcalanmaması ve belirtilen adrese teslimi olarak elde edilirken, en az önemli hususlar ise kargo taşınırken müşteriden yardım istenmesi, firmanın fiziki koşulları ve mevcut kampanyaların uygulanması olarak elde edilmiştir.

Alp vd. (2019) çalışmalarında kargo firmalarının firma itibarını ve müşteri memnuniyetini üniversite öğrencileri açısından değerlendirmiş ve firma itibarının müşteri memnuniyetine etkisini araştırmıştır.

Topal ve Şahin (2019) çalışmalarında kurumsal kargo taşımacılı̆̆ında hizmet kalitesi algısı ve müşteri memnuniyetini 252 kişi ile yüzyüze 
görüşerek araştırmış ve algılanan hizmet kalitesinin beklenenden düşük olduğu bulgusu elde edilmiştir.

Yıldız (2020) çalışmasında kargo firmalarının hizmet kalitesini içerik analizi yöntemiyle incelemiştir. Çalışmada teslimat süresinin uzun olması ve yaşanan gecikmeler kullanıcıların en fazla sorun yaşadığı hususlar olarak belirtilmiş ve hizmet kalitesinin iyileştirilmesinde çalışanların kalifiye olması, müşteri odaklılı̆̆ının olması, hızlı teslimatın olması ve iletişimin etkin olması hususları önerilmiştir.

Kargo hizmetlerinin tüketici davranışlarına etkisini araştıran Duran (2020), Isparta Süleyman Demirel Üniversitesi'nin farklı bölümlerinde eğitim alan 469 öğrenci ile bir anket çalışması yapmış ve lojistik değer, güvenilirlik ve ekonomik gider faktörleri arasında anlamlı bir ilişki tespit etmiştir.

Literatür taramasında da belirtildiği gibi genelde posta ve kargo taşımacılığıyla ilgili kargo firmaları hizmet kalitesi, hizmet kalitesinin tüketici davranışlarına etkisi, müşteri memnuyeti vb. konularda ağırlıklı olarak çalışmalar yapılmış, ETGB ile ilgili bir çalışmaya rastlanmamıştır. Bu nedenle bu çalışmanın literature katkı sağlayacağı düşünülmektedir.

\section{Yöntem}

Posta ve hızlı kargo taşımacılığına olan talebin giderek artması ve gelişimi nedeniyle gümrük işlemlerinin daha seri yapılabilmesi için gümrük idareleri tarafından ETGB hayata geçirilmiştir. 2013 yılında e-ticaret kapsamında yapılan ithal eşyalarının ve e-ihracat işlemleriyle gerçekleştirilen numune alımının daha hızlı ve maliyetinin daha düşük yapılabilmesi için gümrük mevzuatı yeniden güncellenmiştir. $\mathrm{Bu}$ işlemlerde kullanılan ETGB'nin kapsamının belirlenmesinde 10/03/2013 tarihli Seri No: 6 kararı yayınlanmıştır.

İlk başlarda 5 firmanın gümrük idareleri tarafından yetkilendirilmesiyle başlayan bu sistem, 2020 yılında 19 taşıyıcı operator firmanın yetkilendirildiği ve faydalandığı bir noktaya gelmiştir. Bu taşıyıcı firmalar şunlardır: DHL Worldwide Express, UPS Hızlı Kargo, Aramex International, ASE Asya Afrika Hızlı Kargo, MNG Havayolları, MNG Kargo, Yurtiçi Kargo, Dietrich A.B. Lojistik, Dpex Taşımacılık, Eli Uluslararası Taşımacılık, HK Hızlı Kargo, Kargo Atlantıs, Mission Freight, 
Mir Global Lojistik, Paket Taşımacılık Sistemleri, Pan Lojistik, TNT International Express, Solmaz Nakliyat ve Transorient Uluslararası Taşımacılık (Ticaret Bakanlığı, 2020). Küresel ticarette numune akışının ve işlem hızının daha da önem kazanmasıyla birlikte firma sayıları artmaya devam edecektir. Dolayısıyla özellikle ihracat işlemlerinde ETGB'nin kullanımı ve bilinirliği daha da artacaktır.

Çalışmada öncelikle Türkiye'de faaliyet gösteren ve ülke genelinde ETGB ile yapılan işlemlerin \% $70^{\prime}$ den fazlasından sorumlu olan altı büyük firmanın 2018-2020 yıllları verileri değerlendirmeye tabi tutulmuştur. Daha sonra bu firmalarda çalışan uzman görüşleri dikkate alınarak ETGB sürecinin fırsatları, tehditleri, üstünlükleri ve zayıflıkları SWOT analizi yöntemiyle irdelenmiştir.

\section{Bulgular}

Bu başlık altında ilk olarak Türkiye'de sistemi aktif olarak kullanan ve yapılan tüm ETGB işlemlerinin toplamının \%70'inden fazlasını gerçekleştiren yetkilendirişmiş altı operatörün son üç yıllık verileri incelenmiştir. İkinci aşamada ise bu firmalarda bu sürecin işleyişlerinden sorumlu uzman görüşleri yardımıyla sistemin fırsatları, tehditleri, üstünlükleri ve zayıflıkları analiz edilmiştir.

\section{Sistemi Aktif Kullanan Firma Verileri}

Uygulamada sistemin işleyişinden sorumlu olan yetkilendirilmiş 19 firmanın son üç yıllık işlem hacimlerine ulaşılmaya çalışılmıştır. Bu aşamada firmalarla görüşülmüş ve bir çoğu şirket politikası, gizlilik vb nedenlerden dolayı veri paylaşımını reddetmiştir. $\mathrm{Bu}$ nedenle bu bölümde yıllık verilerini bizimle paylaşan altı yetkilendirilmiş global firmanın (Aramex, DHL, UPS, TNT, Ase Asya ve Yurtiçi) işlem hacimlerine yer verilmiştir. Ayrıca Türkiye'de ETGB ile yapılan gümrük işlemlerinin $\% 70$ 'inden fazlası bu altı firma tarafından gerçekleştirilmektedir. Aşağıda Tablo 1.'de 2018 yılına ait ETGB verileri yer almaktadır. 
Tablo 1. 2018 yılı ETGB verileri

\begin{tabular}{|c|c|c|c|c|c|c|}
\hline & \multirow{2}{*}{$\begin{array}{l}\text { ETGB ihracat } \\
\text { Konşimento } \\
\text { Sayisı }\end{array}$} & \multirow[b]{2}{*}{ Beyanname } & \multicolumn{2}{|c|}{ ETGB Vergili İthalat } & \multicolumn{2}{|c|}{ Toplam İşlem Hacmi } \\
\hline & & & $\begin{array}{l}\text { Konşimento } \\
\text { Say1s1 }\end{array}$ & Beyanname & $\begin{array}{l}\text { Konşimento } \\
\text { Sayıs1 }\end{array}$ & Beyanname \\
\hline Aramex & 1035849 & 4275 & 119745 & 1199 & 1155594 & 5474 \\
\hline DHL & 88186 & 331 & 49159 & 257 & 137345 & 588 \\
\hline UPS & 1499929 & 1116 & 188961 & 916 & 1688890 & 2032 \\
\hline TNT & 541080 & 1145 & 120751 & 144963 & 661831 & 146108 \\
\hline Ase & 64947 & 3452 & 92387 & 967 & 157334 & 4419 \\
\hline \multicolumn{7}{|l|}{ Asya } \\
\hline Yurtiçi & 39944 & 180 & 3341 & 262 & 43285 & 442 \\
\hline Toplam & 3269935 & 10499 & 574344 & 148564 & 3844279 & 159063 \\
\hline
\end{tabular}

Tablo 1. incelendiğinde ETGB ile yapılan konşimento sayıları ithalatta gerçekleşen sayılardan fazladır. İthalat için ETGB süreci çok fazla talep görmemekle birlikte küresel ticarette numune akışı ve işlem hızının çok önemli olduğu e-ihracatta rakamların her geçen gün artacağ 1 düşünülmektedir. 2018 yılı Türkiye'de yapılan ETGB işlemlerinin \%70'inden fazlasını gerçekleştiren bu altı firmanın verileri incelendiğinde beyanname sayısının toplamda en yüksek olduğu firmanın TNT olduğu anlaşılmaktadır. Bu altı firmanın 2019 yılı için işlem hacmi Tablo 2.'de verilmiştir

Tablo 2. 2019 yılı ETGB verileri

\begin{tabular}{|c|c|c|c|c|c|c|}
\hline & ETGB ihracat & & ETGB Vergili & İthalat & Toplam İşlem & Hacmi \\
\hline & $\begin{array}{l}\text { Konşimento } \\
\text { Say1s1 }\end{array}$ & Beyanname & $\begin{array}{l}\text { Konşimento } \\
\text { Sayıs1 }\end{array}$ & Beyanname & $\begin{array}{l}\text { Konşimento } \\
\text { Sayıs1 }\end{array}$ & Beyanname \\
\hline Aramex & 1064594 & 4628 & 153793 & 1270 & 1218387 & 5898 \\
\hline DHL & 132164 & 307 & 70938 & 269 & 203102 & 576 \\
\hline UPS & 1146409 & 964 & 13552 & 891 & 1159961 & 1855 \\
\hline TNT & 691584 & 1088 & 127251 & 120513 & 818835 & 121601 \\
\hline $\begin{array}{l}\text { Ase } \\
\text { Asya }\end{array}$ & 51945 & 2816 & 174276 & 2159 & 226221 & 4975 \\
\hline Yurtiçi & 143801 & 244 & 4211 & 283 & 148012 & 527 \\
\hline Toplam & 3230497 & 10047 & 544021 & 125385 & 3774518 & 135432 \\
\hline
\end{tabular}

Yıl bazında değerlendirme yapıldığında ETGB kapsamında 2018 yılında açılan toplam beyanname sayısı 2019 yılından fazladır. 2019 yılı 
verileri bu dört firma için değerlendirildiğinde toplam işlem gören beyanneme sayısı en yüksek olan firma TNT'dir.

Tablo 2. 2020 yılı ETGB verileri

\begin{tabular}{|c|c|c|c|c|c|c|}
\hline & \multirow{2}{*}{$\begin{array}{l}\text { ETGB ihracat } \\
\text { Konşimento } \\
\text { Sayıs1 }\end{array}$} & \multirow[b]{2}{*}{ Beyanname } & \multicolumn{2}{|c|}{$\begin{array}{l}\text { ETGB Vergili İthalat } \\
\text { Konşimento }\end{array}$} & \multicolumn{2}{|c|}{$\begin{array}{l}\text { Toplam İşlem Hacmi } \\
\text { Konşimento }\end{array}$} \\
\hline & & & Say1sı & Beyanname & Say1s1 & Beyanname \\
\hline Aramex & 772491 & 2681 & 119868 & 732 & 892359 & 3413 \\
\hline DHL & 475860 & 2301 & 514319 & 1243 & 990179 & 3544 \\
\hline UPS & 69755 & 1904 & 360527 & 720 & 430282 & 2624 \\
\hline TNT & 1174971 & 1849 & 105529 & 89870 & 1280500 & 91719 \\
\hline Ase Asya & 94198 & 2529 & 154292 & 1493 & 248490 & 4022 \\
\hline Yurtiçi & 10910 & 54 & 1577 & 157 & 12487 & 211 \\
\hline Toplam & 2598185 & 11318 & 1256112 & 94215 & 3854297 & 105533 \\
\hline
\end{tabular}

Covid 19 pandemisi sürecinde kullanıcıların e-ticarete yönelmesi ve eticarete olan taleplerinin artmasıyla ETGB işlem hacminde de artış gözlenmektedir. 2020 yılı ETGB verileri incelendiğinde en fazla artış ithalat işlemlerinde meydana gelmiştir. Bu yılda toplam işlem hacmi en fazla olan firma $\mathrm{TNT}^{\prime}$ dir.

\section{ETGB Süreci SWOT Analizi}

Çalışmanın ikinci bölümünde ETGB sürecinin üstünlükleri, zayıflıkları, fırsatları ve tehditleri belirlenmek amacıyla uzman görüşleri dikkate alınarak SWOT analizine tabi tutulmuştur. Bir faaliyetin, işletmenin veya bir uygulamanın mevcut durumunun değerlendirilmesinde kullanılan en temel ve basit yöntemlerden biri de SWOT analizidir (Akça, 2005: 516). SWOT analizi, sistematik bir araştırma neticesinde elde edilen bulguların değerlendirilmesiyle kaynakların en iyi şekilde kullanımına ve yeni stratejilerin geliştirilmesine olanak sağlayan ve sosyal bilimlerde yaygın kullanılan yöntemlerden biridir. Bu analiz aynı zamanda iç ve diş çevrenin değerlendirilmesine de olanak sağlamaktadır. İngilizcede güçlü yönler ((Strengths), Zayıf yönler (Weakness), Fırsatlar (Opportunities) ve Tehditler (Threats) kelimelerinin ilk harflerinden oluşmaktadır (İnayet ve Akbulak, 2010, s.204).

$\mathrm{Bu}$ çalışmada ETGB sürecinin mevcut durum tespitinin yapılması amacıyla SWOT analizi tekniğinden yararlanılmıştır. ETGB sürecinde 
mevcut sistemde karşılaşılan hataların tespit edilmesine ve düzeltilmesine imkân veren bir araç (Yeşiltaş, 2009:, s.252) olarak bu analiz çalışmada kullanılmıştır. Uygulamanın kullanıcılar ve yetkili operatörler açısından güçlü ve zayıf yönleriyle iç ve dış çevreden kaynaklanan fırsat ve tehditleri tespit edilmiş ve daha kullanışlı bir hale getirilebilmesi için önerilerde bulunulmuştur.

Güçlü yönler: Posta ve Hızlı Kargo Taşımacılı̆̆ı yetkisine sahip operatörlerle yapılan görüşmeler neticesinde mevcut durum tespiti yapılmış ve ETGB sürecinin güçlü yönleri şu şekilde sıralanmıştır:

- Sistem posta ve hızlı kargo taşımacılığı kapsamında havayolu ile taşınan yüklerin 2009 / 15481 sayılı BKK.'in 126. maddesi kapsamında kalan kısmına istinaden yetkili operatörlerce gümrük süreçlerinin kanun ve yönetmeliklere uygun olarak basitleştirilmiş ve düşük maliyetli bir şekilde yapılmasına olanak sağlamaktadır.

- Çok sayıda ara konşimentoyu aynı ETGB'ye baglama imkanı verdiğinden yetkili operatörlere hem kırtasiye hem de zaman avantajı sağlayarak firmaların evrak yoğunluğunu ve iş yükünü hafifletmektedir.

- Türkiye'de faaliyet gösteren ithalat ve ihracat firmalarının rekabet edilebilirlik seviyesini arttırmak amacıyla numune akışının hızlı ve düşük maliyetli bir şekilde gerçekleşmesini sağlamaktadır. Dolayısıyla bu sürecin kullanımıyla mevzuatta güncelleme yapılarak firma talepleri doğrultusunda eşya kilo ve kıymetlerinde yapılan iyileştirmelerle numune gönderilerinin gümrük işlemleri daha seri, kolay ve düşük maliyetli olmaktadır.

- ETGB süreci şahsa gelen eşya için maktu vergi (AB ülkelerinden gelen eşyalar için \%18, diğer ülkelerden gelen eşyalar için \%20) uygulayarak, eşyanın ithalat gözetim önlemleri ve diğer gümrük vergilerine tabi olmadan ve gümrük idarelerini çok meşgul etmeden gümrük işlemlerin yapllabilmesine imkan sağlamaktadır.

- Yolcu eşyalarının basitleştirilmiş işlemlere tabi tutularak gümrük idarelerinin iş yoğunluğunun azalmasına ve daha da işlevsel hale gelmesine imkan sağlamaktadır. 
- Diplomatik eşyaların basitleştirilmiş işlemlere tabi tutulması sağlanarak hızlı teslimine imkan sunmaktadır.

Zayıf yönler: Posta ve Hızlı Kargo Taşımacılığı yetkisine sahip operatörlerle yapılan görüşmeler neticesinde mevcut durum tespiti yapılmış ve ETGB sürecinin zayıf yönleri şu şekilde tespit edilmiştir:

- Gümrük işlemlerinde detaylı beyanın bilinirliğinin yüksek olması ETGB'nin kullanımının yaygınlaşmamasına neden olmaktadır. Bu konuda Ticaret Bakanlığı'na da görev düşmektedir. Ticaret Bakanlığ1 yetkili operatörlerle sürekli etkileşim içinde olmalı, uygulamadaki zayıflıkları tespit etmeli ve gerekli iyileştirmeler yaparak süreci güncellemelidir.

- Uzman ve yetkili operator görüşleri değerlendirildiğinde Seri No:6 kararında ihracatta miktar ve kıymet limitlerinin arttırıldığı buna karşın ithalatta azalttı̆ı ifade edilmiştir. Ayrıca aynı kişi adına bir ayda en fazla 5 taşıma senedi muhteviyatı eşyanın serbest dolaşıma girişine izin verilmiştir. Bu düzenleme ETGB kullanımını azaltmaktadır. Havayoluyla gelen eşyalar depolama sahalarında kalmakta ve depolarda yoğunluğa neden olmaktadır. Aynı zamanda depolama alanlarında kalan gönderilerin tasfiye süreci de hem işlem yoğunluğuna hem de yüksek maliyetlere neden olmaktadır.

- İhracatçlar, KDV iadesinin ETGB sistemine entegrasyonunda sorun yaşamakta, beyan ve özet beyan kapanmaması durumuyla karşı karşıya kalmaktadır. ETGB sisteminin KDV iadelerinde kullanılan VEDOP sistemiyle entegrasyonunda vergi dairelerinde sorunlar yaşanmaktadır. Bu durum gümrük idareleri tarafından kullanılan tek pencere sisteminin iyileştirilmesiyle giderilebilir.

- Yetkili operatörler tarafından ETGB düzenlendikten sonra sistem düzeltme yapılmasına imkan tanımamaktadır. Bu durumda birden fazla ara konşimentonun bağlandığı bir ETGB beyanında firmalar büyük zorluklarla karşı karşıya kalmaktadır. Bir ara konşimentoda yaşanan bir olay diğer ara konşimentoda yer alan firmaları ve ticaretlerini olumsuz yönde etkilemektedir.

- ETGB hizmeti Türkiye'de her gümrük idaresinde verilmemektedir. ETGB'nin olmadığı gümrük idarelerinde 
işlemler uzamaktadır. Bu nedenle bu sistemin ülke genelinde yaygınlaştırılması önerilmektedir.

- Tüm yetkili operatörlerin gerekli teknolojik altyapıya sahip olmaması sürecin bir başka zayıf yönüdür. Belirli teknolojik standartlara sahip olmayan firmalara bu yetkinin verilmesi ileride sürecin olumsuz etkilenmesine ve denetimsizliğe neden olacaktır.

- Yetkili firmalar tarafından tescil alınan ETGB beyannamesine ara konşimentonun sonradan eklenememesi sürecin bir diğer zayıf yönüdür. Bu durum özellikle acil gönderilerde işlemlerin uzamasına neden olmaktadır. Örneğin bir kanser ilacı gönderisi ETGB düzenlendikten sonra sisteme düşerse o beyannameye eklenemeyeceğinden bir sonraki beyana kalacaktır. Bu durum o ilaca ihtiyacı olan hastanın hayatını olumsuz etkileyebilir.

Fırsatlar: Posta ve Hızlı Kargo Taşımacılı̆̆ yetkisine sahip operatörlerle yapılan görüşmeler neticesinde mevcut durum tespiti yapılmış ve ETGB sürecinin fırsatları şu şekilde sıralanmıştır:

- ETGB sisteminde kalem ayırma işleminin basitleştirilmesi, beyanname kapanmadan düzenleme işlemine imkan sağlamaktadır. Dolayısıyla gümrük muanesine tabi tutulan bir eşyanın mevzuata uygun olmadığı tespit edildiğinde ETGB'nin tamamı iptal edilmeden belirtilen gönderi beyandan çıkarılabilmektedir.

- ETGB sürecinde bir çok gönderinin tek bir beyanla işlem yapılmasına olanak sağlanmaktadır. Bu durum özellikle numune ve döküman türü gönderilerde kullanıcılara büyük katkı sağlamaktadır.

- Ticaret Bakanlığı, ETGB uygulamasının başından beri yetkilendirdiği firmaları mevzuat değişiklikleri ve güncellemelerinde sürece dahil ederek gerekli iyileştirilmelerin zamanında yapılmasını sağlamıştır. Bu yaklaşım uygulamada karşılaşılan problemlere anında müdehale etme fırsatı vermiştir ve sistemin eksiklikleri tespit edilerek gerekli düzenlemeler zamanında yapılmıştır.

- Birçok ithalat/ihracat firmasının ve kamu kuruluşlarınında (örneğin devlet hastanelerine gelen tahlil veya döküman 
gönderimi) faydalandığı bu sistemle işlemlerin kapsamı sürekli genişletilmekte ve etkinliği arttırılmaktadır. Bu durum ayrıca gümrük idarelerinin iş yükünün hafiflemesine ve daha önemli konulara zaman ayırabilmelerine fırsat sunacaktır.

Tehditler: Posta ve Hızlı Kargo Taşımacılığı yetkisine sahip operatörlerle yapılan görüşmeler neticesinde mevcut durum tespiti yapılmış ve sürecin tehditleri şu şekilde belirlenmiştir:

- Detayli beyanın kullanımına daha uygun olan BİLGE sistemi hızlı kargo süreçlerinde yetersiz kalmaktadır. Örneğin acil bir ilaç gönderisinde sunulan belgelerde ilaç ile reçete kayıtlarının tutatlı olup olmadığına bakılarak ilacın alıcısına teslim edilmesine imkan vermemektedir.

- Gönderinin gelişinden sonra oluşturulan özet beyan işleminden ETGB talebi yapılması mümkün olmamaktadır. Bu durum gecikmelere ve sürelerin uzamasına neden olmaktadır. Oysaki eşyanın gelişinden sonra düzenlenen özet beyanın ETGB'ye bağlanması, işlem sürecinin hızlanmasını sağlayacaktır.

- Yurtdışına gönderilen ihracat işlemi yapılan bir eşyanın Türkiye'ye geri gelmesinde ayniyat tespitinin yapılmasının mümkün olmaması durumu sistem için bir tehdittir. Bu durum gümrük idarelerinin süreçlerini de olumsuz etkilemektedir. Sisteme bir menu eklenerek fotoğraf aracılığıyla ilgili eşyanın ayniyet tespiti yapılabilir.

- Ihracat gönderilerinde TPSA-HAR kodlu eşyalarda VEDOP sisteminde karşılaşılan sıkıntılar nedeniyle KDV iadesi sorunları yaşanmakta ve bu durum bir tehdit olarak görülmektedir. Kurumlar arasında gerekli güncellemeler yapılarak tek pencere sisteminin etkinliğinin arttırılmasıyla bu durum ortadan kalkabilir.

\section{Bulgular ve Sonuç}

İnternet kullanımının son yirmi yılda artması ve e-ticaretin yaygın kullanımıyla birlikte özellikle uluslararası ürün akışında gümrük süreçleri ön plana çıkmaktadır. Ürüne olan talep her bir gönderinin ithal 
veya ihracatında gümrük işlemlerini etkilemektedir. Bu durum posta ve hızlı kargo taşımacılığı mevzuatının gelişmesine katkı sağlamıştır. Global ürün akışında gümrük işlemleri, yetkilendirilmiş posta ve hızlı kargo taşımacılığı yapan firmalar tarafından ETGB düzenlenerek gerçekleştirilmektedir. 29 Haziran 2019'da 6 Seri No'lu Gümrük Genel Tebliği'nin yayınlanmasıyla brüt ağırlığı $300 \mathrm{~kg}$ ve değeri $15.000 €^{\prime} y u$ geçmeyen ihracat rejimine tabi bir eşyanın gümrük işlemleri ETGB ile yapılabilmektedir. Bu durum ihracatçı firmalar için bir avantaj oluştururken, ithalat işlemlerinde $22 €$ muafiyetinin kaldırılması ithalatçı firmaları veya şahısları olumsuz etkilemektedir. Gümrüklerin etkinliğini de arttıran bu sistem, ithalat ve ihracat işlemlerinde hem gümrük idarelerinin iş yükü azaltmakta hem de ticari değeri olmayan numune, döküman gibi gönderilerin gümrük işlemlerinin hızlı ve etkin yapılmasına olanak tanımaktadır.

Dünyanın birçok yerinde ETGB sistemi günden güne yaygın olarak kullanılmaktadır. Özellikle e-ihracatta kağıtsız beyanname sürecinin başlamasıyla bu uygulamanın kullanımının daha da artacağı tahmin edilmektedir. Bu nedenle ETGB işlemlerinin kapsamının genişletilmesi, yetkili operatörlerin süreç içinde karşılaştıkları sorunların giderilmesi, ticari değeri olmayan gönderilerde hem gümrük idarelerine hem de kullanıcılara sağlayacağı avantajlar açısından son derece önemlidir. ETGB sistemi ile e-ticaret sisteminde ve numune akışında gümrük süreçlerinin basitleştirilmiş, hızlı ve daha düşük maliyetlerle gerçekleştirilmesi sağlanarak ülke ekonomisine ve firma veya şahıslara katkı sağlanmaktadır.

Çalışmada ETGB sürecinin fırsatları, tehditleri, üstünlükleri ve zayıflıkları SWOT analizi yöntemiyle belirlenmeye çalışılmıştır. Eticarette numune akışının artmasıyla birlikte ETGB'nin bu süreci hızlandırması bir üstünlük olarak gösterilmektedir. Diğer taraftan detaylı beyana göre uygulamanın bilinirliğinin daha az olması bir zayıf yöndür. Türkiye'de ETGB işlemini gerçekleştiren yetkili operator sayısında artış yaşanmasına ragmen bu hızlı kargo taşıyıcılarının bazılarının gerekli teknik altyapıya sahip olmadıkları görülmektedir. Aynı zamanda brut kilo ve kıymet limitleri de ETGB uygulamasının kullanımını sinırlayan bir diğer zayıf yöndür. Uluslararası döküman ve numune akışı temel alındığında gümrük idareleri üzerindeki iş yoğunluğunu hafifletmektedir 
fakat bu işlemlerin gerçekleşmesinin belirli gümrük idarelerinde gerçekleşmesi bir diğer zayıf yöndür. Açlan bir ETGB beyanına birden fazla taşıma senedinin eklenmesi uygulamanın güçlü yönünü oluştururken, beyanname tescil edildikten sonra bir ekleme yapılamaması zayıf yönüdür.

ETGB sürecini ve işleyişini konu alan bu çalışmada özellikle uygulamanın zayıf yönleri ve tehditleri üzerinde durulmaktadır. Bu tehdit ve zayıflıklara getirilen önerilerle sistemin daha da iyileştirilmesi amaçlamaktadır. İlerleyen çalışmalarda ETGB sistemini uygulayan yetkili operatörler ve uzman kişilerle görüşülerek istatistiksel analiz yapılabilir. Aynı zamanda Türkiye'deki ETGB uygulamaları ile diğer ülkelerde gerçekleştirilen ETGB uygulamaları karşılaştırılabilir veya ETGB uygulamasının performansı çok kriterli karar verme teknikleri kullanılarak analize tabi tutulabilir. 
EXTENDED ABSTRACT

\title{
The Effects of Electronic Trade Customs Declaration Used in Global E-Commerce System on Post and Express Cargo Transportation
}

\author{
Aynur Acer-Celil Yügünt \\ İstanbul Arel University
}

The widespread use of internet and technology in global trade positively affects the demand for e-commerce. The current COVID pandemic process has affected this system, which is both simple and useful, and has caused its use to increase. The e-commerce system used, It provides many advantages to users such as easy and fast order taking, simple user interfaces, strong e-commerce infrastructure and reliability of purchasing transactions. Organizations and individuals through e-commerce can supply a product they demand at certain standards at a lower cost. Although there are not many obligations in terms of legislation in domestic e-commerce orders, problems may arise due to customs legislation when entering the country for international orders. At the same time, the trade policy measures of the countries are effective in the functioning of the international e-commerce system. However, the increase in global transaction size has led to the simplification of customs procedures applied to shipments and the development of different applications, especially in the field of post and express cargo transportation. Electronic Trade Customs Declaration (ETCD) is one of these applications used to make and simplify customs procedures in import and export in a shorter time. In this process, all customs procedures in import and export are carried out by businesses with post and express cargo transportation authority, that performs transactions through indirect representation on behalf of individuals or companies.

Post and cargo transportation, that has a history of 35-40 years in Turkey, has gained great momentum today. It is known that this sector provides an important added value to our country by providing employment to more than 100 thousand people in Turkey and in 10 thousand fixed centers with 25 thousand vehicles, 7 million address visits 
per a day and 5 million kilometers are covered daily (Kut, 2017). Any global order placed by users may be risky or dangerous for the relevant country and may create a proportionately tax assessment. Shipments such as samples and documents with no commercial value and products with a certain value and amount of customs value are subject to the electronic commerce customs declaration process by applying lump-sum taxation. ETCD, one of the methods applied in e-commerce in Turkey, is extremely important in terms of both the country's economy and national security and in recent years, its use in e-commerce transactions between countries has begun to increase. Due to the increasing and developing demand for post and express cargo transportation, ETCD was implemented by the customs administrations in order to carry out the customs procedures more quickly. This system, that started with the authorization of 5 companies by the customs administrations at the beginning, has reached a stage where 19 carrier operator companies are authorized and benefited from in 2020.

In the study, firstly, the data of six authorized operators, who actively use the system in Turkey and handling more than $70 \%$ of the total of all ETCD transactions, between the years 2018-2020 were examined. When the bill of lading number is examined, it has been found that the ETCD system is mostly used in exports. At the same time, the firm with the highest number of declarations in the relevant years was obtained as TNT. During the Covid 19 pandemic, there is an increase in ETCD transaction volume as users turn to e-commerce and their demands for e-commerce increase. When the 2020 ETCD data is examined, the highest increase occurred in import transactions.

In the second part of this study, strengths, weaknesses, opportunities and threats of the system were evaluated with the SWOT analysis method with the help of expert opinions responsible for the operation of the process in these companies. With the increase in sample flow in ecommerce, it is shown as an strengths that ETCD accelerates this process. On the other hand, it is a weakness that the application has less awareness compared to the detailed declaration. Despite the increase in the number of authorized operators performing ETCD transactions in Turkey, it is seen that some of these express cargo carriers do not have the necessary technical infrastructure. Therewithal, the gross weight and value limits 
are another weakness that limits the use of the ETCD application. Relieves the workload on customs administrations based on international document and sample flow, however the realization of these transactions in certain customs administrations is another weakness. While adding more than one transport waybill to an ETCD declaration opened is the strength of the application, it is a weakness that no additions can be made after the declaration is registered. In this study, that is about the process and operation of the ETCD, especially the weaknesses and threats of the application are emphasized. It's aimed to further improve the system with suggestions for these threats and weaknesses.

\section{Kaynakça / References}

Akça, H. (2006). Assessment of rural tourism in turkey using swot analysis. Journal of Applied Sciences, 6(13), 2837-2839.

Alp, M., Köleoğlu, N. ve Çınar, B. (2019), Kargo firmalarının itibarının müşteri memnuniyetine etkisi. Dumlupinar Üniversitesi Sosyal Bilimler Dergisi, 60, 1-13.

Atmaca, H. E. ve Turğut, D. (2015). Kargo şirketi seçimine yönelik kriterlerin belirlenmesinde Türkiye genelinde bir saha araştırması. Çukurova Üniversitesi İktisadi ve İdari Bilimler Fakültesi Dergisi, 19(2), 65-79.

Çakmak, A. Ç. ve Özkan, B. (2017). Kargo kullanıcılarının önem verdikleri faktörlerin, kargo firmaları tarafından başarım düzeylerinin incelenmesi, Journal of History Culture and Art Research, 6(4), 10101028.

Canpolat, Ö. (2001). E-ticaret ve Türkiye'deki gelişmeler. Ankara: Sanayi ve Ticaret Bakanlığı.

Çınar, M. (2014). Marka bağhllığı oluşumunda örgüt kimliğinin önemi: Posta ve hızlı kargo taşımacıllı̆̆ sektörü üzerinde bir çalışma. Selçuk Üniversitesi Sosyal Bilimler Enstitüsü, Konya.

Deniz, A. ve Gödekmerdan, L. (2011). Müşterilerin kargo firmalarının sunduğu hizmetlere yönelik tutum ve düşünceleri üzerine bir araştırma. Atatürk Üniversitesi Sosyal Bilimler Enstitüsü Dergisi, 15(2), 379-396. 
DHL, Elektronik Ticaret Gümrük Beyannamesi Gönderi Süreci. 23.07.2019 tarihinde $\quad$ https://www.dhl.com.tr/exp-tr/express, adresinden erişildi.

Duran, G. (2020). Kargo hizmetlerinin tüketici davranışlarına etkisi üzerine bir çalışma. Oğuzhan Sosyal Bilimler Dergisi, 2(1), 1-16.

Elibol, H. ve Kesici, B. (2004). Çağdaş işletmecilik açısından elektronik ticaret. Selçuk Üniversitesi Sosyal Bilimler Enstitüsü Dergisi, 11, 303-329.

Emek, U. (2003). Posta hizmetlerinin serbestleştirilmesi: Özelleştirme, rakabet ve regülasyon. Devlet Planlama Teşkilatı

Gümrük Kanunu (4458), 23866 sayılı Resmi Gazete, 04.11 .1999 (5911 sayılı Kanun ile değiştirilmiş hali)

Gümrük ve Ticaret Bakanlığı Yayınları, 01.10.2019 tarihinde https://www.gtb.gov.tr/ adresinden erişildi

http://www.gtb.gov.tr (E.T.: 10.05.2019)

İnayet, Z. ve Akbulak, C., (2010). Troia Tarihi Milli Parkı'ndaki turizm potansiyelinin swot analizi ile değerlendirilmesi, 11. Ulusal Turizm Kongresi, 2-5 Aralık Kuşadası, (Ed. Çolakoğlu, O., E.,), Detay Yayıncılık, 1. Baskı, Ankara, 203-213.

Kut, A. (2017), Kargo sektörü durum analizi ve sektörün geleceği. KARIDD: 27.09.2019 tarihinde http://www.karid.org.tr/kargo-sektorudurumanalizi-ve-sektorun-gelecegi/ adresinden erişildi.

Resmi Gazete, 2018/11510 sayılı 4458 Sayılı Gümrük Kanunu'nun Bazı Maddelerinin Uygulanması Hakkında Kararda Değiş̧iklik Yapilmasına Dair Karar. 11.07.2020 tarihinde https://www.resmigazete.gov.tr/eskiler/2018/04/20180411-1.pdf adresinden erişildi.

Şahbaz, U., Sökmen, A. ve Aytaç, A. (2014). Türkiye'de e-ihracat fırsatlar ve sorunlar.

https://www.tepav.org.tr/upload/files/haber/1415973180-

Tepav, 5.Turkiyede E-Ihracat Firsatlar ve sorunlar.pdf.

Topal, B., ve Şahin, H. (2019). Kurumsal kargo taşımacılığında müşteri memnuniyetinin araştırılması. Akıllı Ulaşım Sistemleri ve Uygulamaları Dergisi, 2(2), 14-26.

Yasalar, T. C. 3065 sayılı Katma Değer Vergisi Kanunu. Ankara: Resmi Gazete (18563 say111), 244. 
Yeşiltaş, M., Çeken, H. ve Öztürk, İ., (2009). Karadeniz bölgesindeki turizm olanaklarının swot analizi ile değerlendirilmesi. Adıyaman Üniversitesi Sosyal Bilimler Enstitüsü Dergisi, 3, 250-269.

Yıldız, B. (2020). Kargo firmaları hizmet kalitesinin içerik analizi. Karamanoğlu Mehmetbey Üniversitesi Sosyal ve Ekonomik Araştırmalar Dergisi, 22(38), 42-57

Yıldız, G. (2014). Son değişiklerle birliktr hızlı kargo taşımacılığı. Gümrük ve Ticaret Dergisi, (3), 53-59.

10.03.2013 tarihli Seri No: 4 Gümrük Genel Tebliği (Posta ve Hızlı Kargo Taşımacılığı). $\quad 13.09 .2020 \quad$ tarihinde https://www.resmigazete.gov.tr/eskiler/2013/03/20130310-5.htm adresinden erişildi.

10705 sayılı Vergi Usul Kanunu, 12.08.2020 tarihinde https://www.mevzuat.gov.tr/mevzuat?MevzuatNo=213\&MevzuatT ur $=1 \&$ MevzuatTertip $=4$

2014/7 Sayll Genelge. $\quad 12.10 .2020 \quad$ tarihinde http://ggm.gtb.gov.tr/data/5331945e487c8eb1e43d7273/2014-7.pdf adresinden erişildi.

29 Haziran 2019 tarihli Seri No: 6 Gümrük Genel Tebliği (Posta ve Hızlı Kargo Taşımacılığı), $\quad 14.08 .2020 \quad$ tarihinde https://www.resmigazete.gov.tr/eskiler/2019/06/20190629-5.htm adresinden erişildi.

3 Aralık 2016 tarihli Seri No: 5 Gümrük Genel Tebliği (Posta ve Hızlı Kargo Taşımacılığı).

https://www.resmigazete.gov.tr/eskiler/2016/12/20161203-15.htm adresinden erişildi.

\section{Kaynakça Bilgisi / Citation Information}

Acer, A. ve Yügünt, C. (2021). Küresel E-Ticaret Sisteminde Kullanılan Elektronik Ticaret Gümrük Beyannamesinin Posta ve Hızlı Kargo Taşımacılığına Etkileri. OPUS-Uluslararası Toplum Araştırmaları Dergisi, 18(Yönetim ve Organizasyon Özel Says1), 1573-1595. DOI: 10.26466/opus.861576. 